\title{
Structural and functional effects of single nucleotide polymorphism on canine cytochrome $b$ 5 reductase - in silico
}

\author{
MUSA, S. Ibrahim \\ Department of Animal Science, Nasarawa State University, Lafia -Campus, Nigeria \\ dribmazara@yahoo.com
}


Available online at www.refaad.com

VMPH 2(3); 2021: 73-76

Research Article

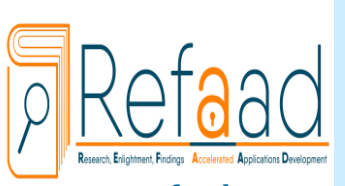

www.refaad.com

\section{Veterinary Medicine and Public Health Journal (VMPH)}

Journal Homepage: https://www.refaad.com/views/vmph/home.aspx

ISSN : 2707-7195(Online) 2707-7187(Print)

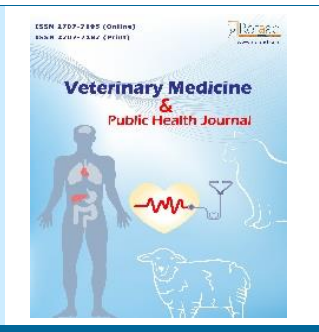

\section{Structural and functional effects of single nucleotide polymorphism on canine cytochrome b 5 reductase - in silico}

\section{MUSA, S. Ibrahim*a}

a Department of Animal Science, Nasarawa State University, Lafia -Campus, Nigeria dribmazara@yahoo.com

* Corresponding author: MUSA, S. Ibrahim, Email: dribmazara@yahoo.com

How to cite this article: MUSA, S. Ibrahim, Structural and functional effects of single nucleotide polymorphism on canine cytochrome b 5 reductase - in silico. Veterinary Medicine and Public Health Journal 2(3); 2021: 73-76.

DOI: https://doi.org/10.31559/vmph2021.2.3.2 Received Date: 21/10/2021 Revised Date: 7/11/2021 Accepted Date: 27/11/2021

\section{Abstract}

The objectives of this study were to investigate the effects of single nucleotide polymorphism in Canine cytochrome b5 reductase using computational methods. Data was obtained from database of National Centre for Biotechnology Information (db SNP) and computational software was used for the analysis. The 3D protein structure was predicted using phyre 2 server. PANTHER analysis predicted the effect of single nucleotide polymorphism (substitution of Isoleucine for Leucine at position 194) as damaging. Analysis using the Mutpred 2 web application also indicated deleterious effects of the amino acid substitution. Molecular mechanisms of structural changes in the amino acid were determined using Mutpred 2 to be altered ordered interface, gain of allosteric sites and altered metal binding. The study indicated that the substitution of Isoleucine by Leucine at position 194 of the amino acid sequence (Ile 194 Leu) resulted in the destabilization of the amino acid structure leading to functional deviation in canine cytochrome b5 reductase.

Keywords: CYB5R3; Gene variant; In silico analysis; 3D structure. 


\section{Introduction}

Single nucleotide polymorphism plays a significant role in functional deviation of proteins resulting in many diseases (Brijash and Kinnari, 2014). A major pathway for sulphonomide detoxification is $\mathrm{N}$ acetylation, impaired $\mathrm{N}$ acetylation appears to be a risk factor for sulphonamide hypersensitivity (Funk-keenan et al., 2012). Both somatic and the soluble (Erythrocytic) forms of cytochrome b5 reductase are encoded by the cytochrome b 5 reductase (CYB5R3) gene (Roma et al., 2006). The enzyme is primarily responsible for the maintenance of hemoglobin in its reduced and active form (Scott et al., 2002). The association between methemoglobinemia and some variants of cytochrome b5 reductase has been established in some breeds of dogs (Shino et al., 2018). Nonsynonymous single nucleotide polymorphisms have been reported to affect protein expression and enzymatic activity of cytochrome b 5 reductase. Sulphonamide hypersensitivity has been documented in dogs in an average of 12 days following sulphonamide administration (Trepanier et al., 2003). Clinical signs associated with sulphonamide hypersensitivity include fever, hepatic disorder, cutaneous lesions, proteinuria, and neurological signs. The disorder appears to be overexpressed in some breeds of dogs which indicate a genetic predisposition (Reinhart et al., 2018). Protein functions may be altered by altering protein solubility or by destabilizing protein structure (Brijash and Kinnari, 2014).

Protein analysis through evolutionary relationship is a resource for gene analysis based on evolutionary history and functions (Huaiyu et al., 2019). The server uses gene ontology tool for functional classification. Mutpred 2 is a software package that integrates genetic and molecular data to predict the pathonenicity of amino acid substitution (Vikas et al., 2017). It provides both pathogenic predictions and a list of specific potential molecular alterations (Jain et al., 2016). The effects of substitution of Isoleucine by Leucine in position 194 of amino acid sequence of canine cytochrome b5 reductase were evaluated in this study. The canine cytochrome B5 reductase is a potential biomarker for sulphonomide hypersensitivity in dogs. The objectives of this study were to investigate the functional and structural effects of single nucleotide polymorphism in canine cytochrome B5 reductase.

\section{Materials and Methods}

Data on canine cytochrome b5 reductase with accession numbers >ABA12483.1 was retrieved from $\mathrm{db}$ SNP database of National Centre for Biotechnology Information (NCBI) and used for analysis.

\section{Determination of 3D structure:}

The 3D structure of canine cytochrome b 5 reductase was determined using phyre 2 server
(Version 2.0, Imperial College London, United Kingdom). The tool was used to analyze and predict protein structure, function, and mutations (Kelly et al., 2015). The server uses advanced detection techniques to build 3D models and analyze effects of amino acid variants using protein sequences. The method relies on profiles or hidden markkov models (Yates et al., 2014).

\section{Analysis of single nucleotide polymorphism using Panther:}

Panther (Version 15.0, University of Southern California, United States of America) estimates the likelihood that a non-synonymous SNP will cause a functional impact on the protein as described by Tang and Thomas, 2016.

\section{Analysis of single nucleotide polymorphism using MutPred 2:}

The Mutpred 2 server (Version 2.0, Indiana University, United State of America) was used to predict the functional and structural effects of single nucleotide polymorphism on canine cytochrome B5 reductase as described by (Kelly et al., 2017).

\section{Results and Discussion}

Analysis using MutPred 2 indicates damaging effects of substitution of Isoleucine by Leucine at position 194 of the amino acid sequence. The molecular mechanisms of structural changes in the amino acid sequence were predicted to be altered binding sites as shown in Table 1.

The three dimensional (3D structure) of canine cytochrome B5 reductase was predicted using Phyre 2 server as shown in Figure 1.

Panther software predicted the effects of substitution of Isoleucine by Leucine at position 194 of amino acid sequence of canine cytochrome b5 reductase as damaging. The result is shown in Table 2.

Sulphonomide detoxification in dogs is carried out largely by reduction of the reactive sulphonomide hydroxylamine metabolite by cytochrome b5 reductase (Shino et al., 2018). Acquired methemoglobinemia occurs following exposure to drugs or oxidizing agents such as sulphonamides, whereas congenital methemoglobinemia is associated with deficiency of cytochrome b5 reductase in dogs (Jaffey et al., 2017). Hemoglobin is maintained in reduced functional state by biologically reducing mechanisms involving cytochrome b5 reductase enzyme.

This study indicates that analysis of single nucleotide polymorphism in canine cytochrome b5 reductase provides better understanding of genetic markers of drug hypersensitivity in dogs. The results demonstrate the potential use of canine cytochrome b5 reductase as a genetic marker for sulphonamide hypersensitivity in dogs. The knowledge is useful in preventing the application of incriminating drugs in susceptible animals in order to eliminate the 
occurrence of drug hypersensitivity. The study indicated that the substitution of Isoleucine by Leucine at position 194 of the amino acid sequence
(Ile $194 \mathrm{Leu}$ ) resulted in the destabilization of the amino acid structures leading to functional deviation in canine cytochrome b5 reductase.

Table (1): Predicting the effect of substitution of leucine by isoleucine at position 194 of canine cytochrome b5 reductase using Mutpred 2 server (Version 2.0, Indiana University)

\begin{tabular}{lll}
\hline Parameters & $\begin{array}{l}\text { Predicted } \\
\text { conservation } \\
\text { score/Probability }\end{array}$ & P - Value \\
\hline Mutpred 2 score & 0.620 & - \\
Altered ordered interface & 0.30 & 0.02 \\
Gain of allosteric site & 0.29 & 0.03 \\
Altered metal binding & 0.26 & 0.03 \\
\hline
\end{tabular}

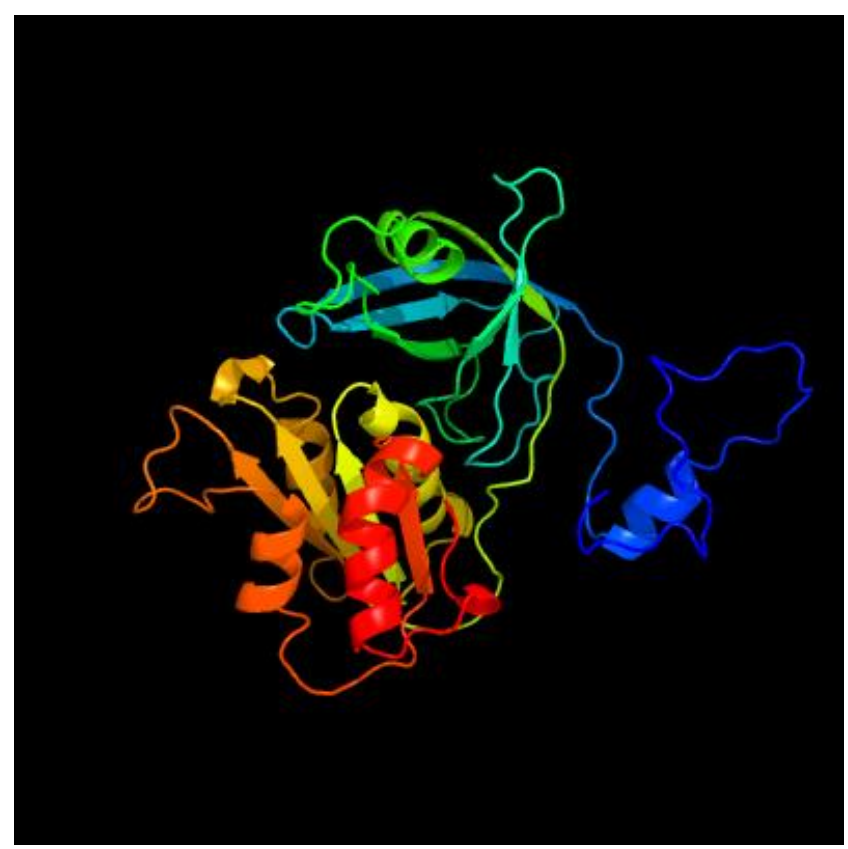

Figure (1): 3 D structure of canine cytochrome b5 reductase

\section{PANTHER HMM: NADH- CYTOCHROME B5 REDUCTASE (PTHR19370)}

Table (2): Analysis of effects of single nucleotide polymorphism using PANTHER software/ Version 15.0 (2020)

\begin{tabular}{l}
\hline Substitution $\quad$ preservation time \\
\hline I194L 673 \\
PSEP (position-specific evolutionary preservation) measures the length of time (in millions of years) a position in current \\
protein has been preserved by tracing back to its reconstructed direct ancestors. The longer a position has been preserved, \\
the more likely that it will have a deleterious effect. The thresholds we chose were: "probably damaging" (time $>450$ my, \\
corresponding to a false positive rate of $\sim 0.2$ as tested on HumVar), "possibly damaging" (450my $>$ time $>200$ my, \\
corresponding to a false positive rate of $\sim 0.4$ ) and "probably ben ign" (time $<200$ my). \\
\hline
\end{tabular}

\section{References}

1. Brijash, D. \& Kinnari, N. M. (2014). In silico analysis of single nucleotide polymorphism in human TNF alpha gene. Meta gene, 2: 586- 595. https://doi.org/10.1016/j.mgene.2014.07.005

2. Funk-keenan, J., Sacco, J., Wang, Y.Y., Rosimasen, S., Motsinger, A. \& Trepanier, L. A. (2012). Evaluation of polymorphism in the sulfonamide detoxification gene, CYB5A And CYB5R3 in dogs with sulfonamide hypersensitivity. Journal of Veterinary Internal Medicine, 26 (5): 1126- 1133. https://doi.org/10.1111/j.1939-1676.2012.00965.x

3. Huaiyu, M., Anushiya, M., Dustin, E., Xiaosong, H. \& Paul, D.J. (2019). Panther version 14: More genome, a new panther go - slum and improvements in enrichment analysis Tools. Nucleic Acid Research, 47: 419-426. https://doi.org/10.1093/nar/gky1038

4. Jaffey, J. A., Harmon, M. R. Villani, N. A., Creighton, E. K. Johnson, G. S. Giger, U. and Dodam, J. R. (2017). Long- term treatment with methylene blue in a Dog with Hereditary methemoglobinemia caused by cytochrome b5 reductase deficiency. Journal of Veterinary Internal Medicine, 31 (6): 1860- 1865. https://doi.org/10.1111/jvim.14843

5. Jain, S., White, M. \& Radivojal, P. (2016). Estimating the class prior and postterm from noisy positives and unlabeled data: In advances in neural information processing systems, 2693 - 2701. 
6. Kelley, L. A., Mezudis, S., Yates, C. M., Wass, M.N. \& Stenberg, M. J. (2015). The phyre 2 web portal for protein modelling, prediction and analysis. Nature Protocols, 10: 846- 858. https://doi.org/10.1038/nprot.2015.053

7. Reinhart, J. M., Ekena, J., Cioffi, A. C. \& Trepanier, L. A. (2018). A single nucleotide Polymorphism in canine cytochrome b5 reductase gene is associated with sulfonamide hypersensitivity and is over presented in Doberman Pinschers. Journal of Veterinary Pharmacology and therapeutics. 41 (3): 402- 408. https://doi.org/10.1111/jvp.12478

8. Roma, G., Crowly, L. \& Barber, M. (2006). Expression and characterization of a Functional canine variant of cytochrome b5 reductase. Archives of Biochemistry and Biophysics, 452 (1): 69 - 82. https://doi.org/10.1016/j.abb.2006.04.021

9. Scott, C.D., Clare, F.K., Lee, M. Rhoda, E.H., \& John, P.H. (2002). Role of redox potential of hemoglobinbased oxygen carriers on methemoglobin reduction by plasma components. Artificial cells, Blood substitutes and Biotechnology, 30(1): 39-51. https://doi.org/10.1081/bio-120002726

10. Shino, H., Ofsaka, Y., Sato, T., Doi, K., Inanami, O. \& Yamasaki, M. (2018). Familial Congenital
Methemoglobinemia in pemeramian dogs caused by a missense variant in the NADH cytochrome b5 reductase gene. Journal of Veterinary Internal Medicine. $\quad 32(1) \quad: 165-171$. https://doi.org/10.1111/jvim.15031

11. Tang, H. \& Thomas, P. D. (2016). Panther- PSEP: Predicting disease causing genetic variants Using positive -specific evolutionary preservation. Bioinformatics, $\quad 32 \quad$ (14): $2230-22$. https://doi.org/10.1093/bioinformatics/btw222

12. Trepanier, L. A., Danht, R., Toll, J. \& Watrous, D. (2003). Clinical findings in 40 dogs with hypersensitivity associated with administration of potentiated sulfonamide. Journal of Veterinary Internal Medicine., 17 (5): 647 - 652. https://doi.org/10.1111/j.1939-1676.2003.tb02495.x

13. Vikas, P., Jorge, W., Guar, N. L. \& Hyun, N. (2017). Mutpred 2: Infeering the molecular Phenotypic impacts of amino acid variants. Bio RXiV, http://doi.org/10.1101

14. Yates, C.M., Fillipis, I., Kelly, L.A. \& Steignberg, M.J.E. (2014) Suspect: Enhanced Prediction of single amino acid variant phenotype using network features. Journal Of Molecular Biology, 426(14): 2692-2701. https://doi.org/10.1016/j.jmb.2014.04.026 